\title{
Placental Malaria is associated with reduced early life weight development of affected children independent of low birth weight
}

\author{
Brigitte Walther ${ }^{1 *}{ }^{*}$, David JC Miles ${ }^{1,2+}$, Sarah Crozier ${ }^{1,3}$, Pauline Waight ${ }^{1,4}$, Melba S Palmero ${ }^{1,5}$, Olubukola Ojuola ${ }^{1,6}$,
} Ebrima Touray ${ }^{1}$, Marianne van der Sande ${ }^{1,7}$, Hilton Whittle ${ }^{1}$, Sarah Rowland-Jones ${ }^{1,8}$, Katie L Flanagan ${ }^{1}$

\begin{abstract}
Background: Infection with Plasmodium falciparum during pregnancy contributes substantially to the disease burden in both mothers and offspring. Placental malaria may lead to intrauterine growth restriction or preterm delivery resulting in low birth weight (LBW), which, in general, is associated with increased infant morbidity and mortality. However, little is known about the possible direct impact of the specific disease processes occurring in PM on longer term outcomes such as subsequent retarded growth development independent of LBW.

Methods: In an existing West-African cohort, 783 healthy infants with a birth weight of at least 2,000 $\mathrm{g}$ were followed up during their first year of life. The aim of the study was to investigate if Plasmodium falciparum infection of the placenta, assessed by placental histology, has an impact on several anthropometric parameters, measured at birth and after three, six and 12 months using generalized estimating equations models adjusting for moderate low birth weight.

Results: Independent of LBW, first to third born infants who were exposed to either past, chronic or acute placental malaria during pregnancy had significantly lower weight-for-age $(-0.43,95 \% \mathrm{Cl}$ : $-0.80 ;-0.07)$, weight-forlength $(-0.47,95 \% \mathrm{Cl}:-0.84 ;-0.10)$ and BMI-for-age $z$-scores $(-0.57,95 \% \mathrm{Cl}:-0.84 ;-0.10)$ compared to infants born to mothers who were not diagnosed with placental malaria ( $p=0.019,0.013$, and 0.012 , respectively). Interestingly, the longitudinal data on histology-based diagnosis of PM also document a sharp decline of PM prevalence in the Sukuta cohort from 16.5\% in 2002 to $5.4 \%$ in 2004.

Conclusions: It was demonstrated that PM has a negative impact on the infant's subsequent weight development that is independent of LBW, suggesting that the longer term effects of PM have been underestimated, even in areas where malaria transmission is declining.
\end{abstract}

\section{Background}

Despite the availability of appropriate tools to control malaria and recently strengthened efforts to employ them efficiently [1], the latest estimates still consider 3.3 billion people at risk of acquiring malaria each year. In 2006, 247 million malaria cases were reported, causing almost one million deaths [2]. Approximately 50 million pregnant women are at risk of malaria, more than $50 \%$ of whom live in areas of sub-Saharan Africa with intense

\footnotetext{
* Correspondence: bwalther@mrc.gm

+ Contributed equally

${ }^{1}$ MRC Laboratories, Atlantic Boulevard, Fajara, PO Box 273 Banjul, The Gambia
}

(c) 2010 Walther et al; licensee BioMed Central Ltd. This is an Open Access article distributed under the terms of the Creative Commons Attribution License (http://creativecommons.org/licenses/by/2.0), which permits unrestricted use, distribution, and reproduction in any medium, provided the original work is properly cited. areas at least one in four pregnant women (all parities) has evidence of malaria infection at delivery defined as either peripheral malaria or placental malaria (PM) $[4,5]$. Where transmission is low, peripheral and placental parasitaemia prevalence was estimated as $13.7 \%$ and $6.7 \%$, respectively [6].

The deleterious effects of malaria in pregnancy on the morbidity and mortality of fetuses and newborns are well recognized. The impact of PM on the mother depends on the level of acquired immunity and is more severe in non-immune women. In highly endemic areas, where women can be assumed to be partially immune, 
the frequency and severity of the infection is highest in primigravidae. The main effects of malaria in pregnancy on birth outcomes are thought to be mediated by maternal anaemia $[7,8]$ and placental insufficiency [9-13]. Both factors have been suggested to act together to cause either intrauterine growth restriction (IUGR) [14] or preterm delivery $[15,16]$, leading to low birth weight (LBW) [17-19]. A number of studies have demonstrated a firm association between PM and LBW $[4,5,13,20]$, and in general, LBW itself is known to be highly associated with infant morbidity and mortality $[21,22]$. Likewise, in children born to mothers with PM, the associated LBW has been suggested as a major risk factor for neonatal and infant mortality [23-25]. It has been estimated that PM causes 167,000967,000 cases of LBW in Africa, associated with 62,000-363,000 newborn deaths each year [4,26]. However, it has been emphasized that these infant deaths are not due to the impact of LBW alone, but to the general disease processes which have resulted in LBW [27]. In addition, PM has been associated with a twofold increase in risk of stillbirth [28], and may put the foetus at increased risk of congenital cytomogalovirus infections [29]. While the immediate consequences of PM and LBW on neonatal and infant morbidity and mortality have been studied extensively, comparatively little is known about the possible long-term impact of PM on the subsequent development of the child. To date only one study has shown that 12 month old infants exposed to maternal malaria at delivery (placental or peripheral) were lighter and thinner than children who were not exposed to PM [30], even after controlling for low birth weight.

Since LBW in itself, regardless of the underlying processes, has been associated with inhibited growth, impaired cognitive development, and increased incidence of chronic diseases later in life [31], it is difficult to study potential direct effects of PM on the subsequent development of the child that are independent of the effects caused by the associated LBW. This study addressed whether PM has an additional or 'independent' effect on growth development, apart from the known effects of PM following the causal pathway (exposure to $\mathrm{PM} \rightarrow \mathrm{LBW} \rightarrow$ incomplete catch-up growth [30] $\rightarrow$ growth retardation). The direct impact of PM on the child's subsequent growth development during the first year of life was investigated by using data from an ongoing Gambian cohort study, which was specifically designed to enroll healthy babies, excluding those with a birth weight below 2,000 g. This study design and subsequent analysis adjusting for moderate low birth weight $(2,000 \mathrm{~g}-2,499 \mathrm{~g})$ offered the unique opportunity to study the impact of PM independent of LBW or overt co-morbidity.

\section{Methods}

\section{Study participants and recruitment}

Data were collected from children born between January 2002 and July 2005 as part of an ongoing open cohort study at the maternity ward of the Health Centre in Sukuta, a semi-urban Gambian village $30 \mathrm{~km}$ south of the capital Banjul, where malaria transmission varies considerably between season, with highest incidence during the wet season and immediately afterwards ('malaria season': August - December). The main study, as well as the analysis strategy of the data presented here, was approved by the Joint Gambian Government/ MRC Ethics Committee. The newborns delivered at the maternity ward were enrolled after informed consent of the mother was obtained. The purpose of the main cohort was to study immune responses of infants to vaccines and infections. Since overt morbidity, as well as risk factors associated with LBW, are known to increase susceptibility to infectious diseases and thus bias any immunological responses [32-35] only healthy singleton children were eligible for recruitment into the cohort. Newborns below a birth weight of 2,000 g were excluded from the study.

A survey among Gambian pregnant women in 200001 [36] estimated the prevalence of HIV to be $1.0 \%$ (CI: $0.9-2.4 \%)$ in Serekunda, an urban settlement approximately $10 \mathrm{~km}$ from Sukuta. Based on this estimate, HIV + cases are unlikely to have significantly impacted on the results of this study, and following ethical guidance HIV testing was not performed.

\section{Study Design}

Demographic, anthropometric and clinical data from 783 mother/child pairs were used to investigate the association of maternal PM and height and weight in the first year of life of the offspring. Basic demographic and socio-economic data, such as, ethnicity, age, and parity of the mother, education of the parents and, as a measure for overcrowding, number of persons sleeping in one bedroom, as well as information on malaria treatment and bednet use were collected in face-to-face interviews by trained fieldworkers using questionnaires shortly after birth. Infants were followed up monthly over a 12-month period for morbidity and anthropometric measurements. At each follow up visit trained nurses recorded the number of illness episodes during the previous month reported by the mother or guardian of the child and administered vaccines according to the recommended Gambian Expanded Programme of Immunization schedule. Maternal height and weight were recorded six months after delivery.

PM status was defined by placental histology. After birth a placental biopsy was taken and embedded in paraffin and stained for histological analysis of PM status 
[29]. Cases were classified according to Ismail [37] as active infection (presence of infected red blood cells in the intervillous space of the placenta) and past infection (no parasites, but haemozoin deposition in macrophages). Active infection was further subdivided into acute infections (only parasites and minimal haemozoin deposition) and chronic infections (parasites and significant haemozoin deposition).

Childrens' weight and length measurements at three, six and 12 months of age (+/- 15 days) were used to calculate four age/gender-standardized indicators: 'weightfor-age' (wfa), 'length-for-age' (lfa), 'weight-for-length' (wfl) and 'body-mass-index-for-age' (BMIfa) based on the WHO "Child Growth Standards, 2006" using the Stata macro 'igrowup.ado'[38].

\section{Statistical methods}

All data were double entered into an Access database (Microsoft), validated and checked for range and consistency. Prior to investigating if PM is associated with infant's size and nutritional status, univariable analyses were used to assess whether known PM risk factors (young maternal age, low parity, low socio-economic status, no bednet use, and seasonality of malaria transmission) [6] were present in this study population. A logistic regression model was fitted including all risk factors with p-values less than 0.2 in univariable analysis, which were kept in the model at a significance level $\mathrm{p} \leq 0.05$. The final model including parity, PM season and year, and duration of schooling of the mother was used to calculate adjusted ORs and corresponding $\mathrm{p}$ values of being $\mathrm{PM}+$ comparing the individual exposure groups to a specified baseline group.

The hypothesis that exposure to PM would be associated with lower values for anthropometric indicators was tested at each of the three time points three, six and 12 months using univariable analyses first. Additional mother and child characteristics such as maternal age, height, BMI, parity, duration of schooling, living in crowded housing conditions as well as gender of the child, moderate low birth weight of 2,000 g - 2,499 g, current age of the child, month and year of birth, and whether the child was born in the 'hungry' season (during the months with intensive rain fall from July to October) $[39,40]$ were investigated as risk factors for reduced indicators. Univariable analyses were conducted to examine the association of each factor with the four anthropometric indicators described above at three, six and 12 months of age.

Cross-sectional times series models using generalized estimating equations (GEE) to fit the parameters of the models with exchangeable correlation structure were then constructed for each anthropometric indicator. The final models account for multiple weight and length measurements at three, six and 12 months of age and confounding factors such as sex, moderate low birth weight of 2,000 g - $2.499 \mathrm{~g}$, infant's age, birth month and year, parity and education (duration of schooling) of the mother. An interaction term was included for PM exposure status of the child and parity to investigate if the association of PM and size of the infant varied between parity groups. Since the association of PM and the growth indicators wfa, wfl and BMIfa was not significantly different for two or three pregnancies, but for more than four pregnancies compared to the first pregnancy, data was split into two groups according to 1-3 and 4 and more pregnancies. Maternal age and living in crowded housing conditions lacked a significant association with z-scores and was therefore not included in the final models. Mother's height and BMI were not considered, since $61 \%$ of the data were missing. No difference was seen for anthropometric measurements taken during or after the 'hungry' season; thus "hungry season" was not included in the models. The resulting models were used to assess the effect of PM exposure on each anthropometric indicator independent of birth weight.

Whether maternal exposure to PM was associated with being underweight, wasted or stunted (wfa, wfl or lfa $\mathrm{z}$-scores $<-2$, respectively) was investigated using logistic regression. Odds ratios for the group of wasted or underweight infants and a second group of stunted infants were calculated choosing all the remaining wellnourished infants as the baseline group.

\section{Results}

\section{Baseline characteristics of the study population}

Available data from 783 mother/child pairs, collected between January 2002 and July 2005 were analysed. In each year, with the exception of 2005, a comparable number of babies were enrolled and genders were equally distributed with $54.2 \%$ (SD $0.5 \%$ ) being male. Mean birth weight and length were 3,045 g (SD $449 \mathrm{~g}$ ) and $48.5 \mathrm{~cm}$ (SD $2.2 \mathrm{~cm}$ ), respectively. 80 babies (10.3\%) had a birth weight of 2,000 g - 2,499 g. Mean maternal age was 25.6 years (SD 5.5 years). 74 (9.5\%) placentas were $P$. falciparum infected; $37 / 74$ (50\%) of which were classified as active infection, which was further subdivided into $21 / 74(28.4 \%)$ acute and 16/74 (21.6\%) chronic infections. The remaining $50 \%$ were classified as past infected. Further maternal and child characteristics are summarized in Table 1.

\section{Factors associated with PM}

The cohort was assessed for known risk factors for PM [6]. As has been described previously, PM was significantly associated with first pregnancy and lower socioeconomic status of the mother. However, in this cohort initial univariable analysis did not reveal a significant association of maternal age, BMI, ethnicity, treatment for malaria and bednet use with PM (Additional file 1). 
Table 1 Baseline characteristics of the study population for 2002-05

\begin{tabular}{|c|c|c|}
\hline $\begin{array}{l}\text { Maternal characteristics, } \\
\mathrm{N}=783\end{array}$ & No & (\%) \\
\hline \multicolumn{3}{|l|}{ Age of the mother } \\
\hline Age $<20$ & 99 & $(12.6)$ \\
\hline Age $20-24$ & 252 & $(32.2)$ \\
\hline Age 25-29 & 219 & $(28.0)$ \\
\hline Age $\geq 30$ & 179 & $(22.9)$ \\
\hline Unknown & 34 & (4.3) \\
\hline \multicolumn{3}{|l|}{ Number of pregnancies } \\
\hline First & 153 & $(19.5)$ \\
\hline Second & 173 & $(22.1)$ \\
\hline Third & 123 & $(15.7)$ \\
\hline Fourth & 100 & $(12.8)$ \\
\hline Fifth & 81 & $(10.4)$ \\
\hline Sixth or more & 153 & $(19.5)$ \\
\hline \multicolumn{3}{|l|}{ Mother's ethnic group } \\
\hline Mandinka & 426 & $(54.4)$ \\
\hline Fula & 95 & $(12.1)$ \\
\hline Wolof & 87 & $(11.1)$ \\
\hline Jola & 78 & $(10.0)$ \\
\hline Serere & 37 & (4.7) \\
\hline Serahula & 22 & (2.8) \\
\hline Manjago & 11 & (1.4) \\
\hline Other & 27 & (3.5) \\
\hline \multicolumn{3}{|c|}{ Duration of education of the mother } \\
\hline $0-4$ years & 199 & $(25.4)$ \\
\hline 5 and more years & 403 & $(51.5)$ \\
\hline Unknown & 181 & $(23.1)$ \\
\hline \multicolumn{3}{|l|}{ Placental malaria } \\
\hline Not infected & 709 & $(90.6)$ \\
\hline Acute & 21 & (2.7) \\
\hline Chronic & 16 & (2.0) \\
\hline Past & 37 & (4.7) \\
\hline \multicolumn{3}{|c|}{ Baby's characteristics, $N=783$} \\
\hline \multicolumn{3}{|l|}{ Year of birth } \\
\hline 2002 & 164 & $(21.0)$ \\
\hline 2003 & 218 & $(27.8)$ \\
\hline 2004 & 277 & $(35.4)$ \\
\hline 2005 (January - July) & 124 & $(15.8)$ \\
\hline
\end{tabular}

In the presented study, maternal anaemia, a consequence of PM known to be associated with LBW $[13,17,41-44]$ was not associated with PM and newborns in the PM+ group were not significantly lighter than newborns in the PM- group (Additional file 2). During the one year follow up infants in both comparison groups suffered a similar number of all-cause morbidity episodes.

Lower z-scores for anthropometric indicators for children born to PM+ mothers independent of LBW

To assess the impact of PM status at birth on growth development during the first year of life, 1,491 (PM+:
137, PM-: 1354) z-scores for each of four anthropometric indicators (wfa, lfa, BMIfa, and wfl) were analysed (528 at three months, 510 at six months and 453 at 12 months of age). At all time points mean z-scores for wfa, lfa, and BMIfa were significantly lower than zero (mean range across age: wfa: -0.59 to -0.26 ; lfa: -0.67 to -0.27 ; and BMIfa: -0.29 to -0.10 ), indicating that Gambian children recruited in the cohort were lighter, smaller, and had lower values for BMI than children of the world standard population with same sex and age characteristics $(\mathrm{p}<0.0001)$. Mean wfl z-scores were significantly lower than zero at six months $(-0.05, \mathrm{p}=$ $0.038)$ and 12 months $(-0.36, \mathrm{p}<0.0001)$, but not at three months $(0.06, \mathrm{p}=0.565)$.

Using univariable analysis comparing children born to $\mathrm{PM}+$ mothers with those born to PM- mothers, infants exposed to PM had at least borderline significantly lower mean z-scores for all four anthropometric indicators at 12 months (Figure 1). Mean differences ranged from 0.29 z-scores (CI: 0.18 ; 0.40$)$ to $0.60 \mathrm{z}$-scores (CI: $0.48 ; 0.70)$. The mean differences in z-scores between 12 and three months were not significantly different between PM+ and PM- groups (wfa: $\mathrm{p}=0.738$, lfa: $\mathrm{p}=$ 0.790, BMIfa: $\mathrm{p}=0.9995$, and wfl: $\mathrm{p}=0.668$ ).

Longitudinal analysis using generalized estimating equations (GEE) accounting for multiple measurements for infants at different time points, and for risk factors for low anthropometric indicators such as parity and duration of maternal education, moderate low birth weight $(2,000 \mathrm{~g}-2.499 \mathrm{~g})$, gender, month and year of birth, revealed that wfa, BMIfa and wfl z-scores were significantly associated with maternal PM status for first to third borns. However, PM exposure had no effect on lfa z-scores (Table 2).

Figure 1, representing the raw data for each of the four anthropometric indicators at the three time points for $\mathrm{PM}+$ and PM- groups, implies that the impact of $\mathrm{PM}$ on anthropometric indicators might be stronger within the third age group than within the first two groups. The tests for an interaction of PM and age for the final GEE models adjusting for confounding factors such as gender, duration of maternal education and parity, moderate low birth weight, birth month and year of the infant were not significant. The presented data do therefore not support the hypothesis of an effect gradation with increasing age.

At the age of three, six and 12 months $20.1 \%, 9.6 \%$, and $22.2 \%$ of the infants in the PM+ group were either wasted, underweight or stunted compared to $14.2 \%$, $13.1 \%$, and $17.0 \%$ in the PM- group, respectively. The odds for wasting or being underweight were 2.4 and 3.1 times higher in the PM exposed group at the age of three and 12 months respectively, but did not reach significance ( $p=0.095$ for both). Infants of the PM+ 
groups were not significantly more likely to be stunted compared to infants of the PM- group within any age group.

\section{Steady decline in PM prevalence from January 2002 to} July 2005

As shown in Figure 2, the percentage of mothers with PM seen at the Sukuta Health Centre decreased significantly from $16.5 \%(27 / 164)$ in 2002 , to $5.4 \%(15 / 277)$ in 2004 ( $\left.\mathrm{p}_{\text {trend }}<0.0001\right)$. For 2005 , data were available for the non transmission season only (January to July), but the risk of PM during the non transmission season was significantly lower in 2004 and 2005 than in 2002 (odds ratio $(\mathrm{OR})_{2004} 0.42, \mathrm{CI}(0.18 ; 0.95), \mathrm{p}=0.038, \mathrm{OR}_{2005}$
0.08 , CI (0.02; 0.37), p-value $=0.001$, respectively), with a highly significant trend ( $\mathrm{p}_{\text {trend }}<0.001$ ).

Influence of seasonal malaria transmission on PM prevalence

The majority of PM cases (55/74, 76\%) were diagnosed during the months of October to March (OR 2.85, CI (1.62; 5.03), $\mathrm{p}<0.0001)$. Mothers delivering during the malaria transmission period (August to December) were more likely to be diagnosed with acute PM compared to mothers delivering during the non-transmission period from January to July (OR 3.00 , CI $(1.16 ; 7.79), \mathrm{p}=$ $0.024 ; \mathrm{p}_{\text {trend }}<0.011$ [AOR 3.00, CI $(1.14 ; 7.94), \mathrm{p}^{*}=$ 0.026 , $\left.\mathrm{p}_{\text {trend }}=0.014\right]$ ). By contrast, seasonality of malaria

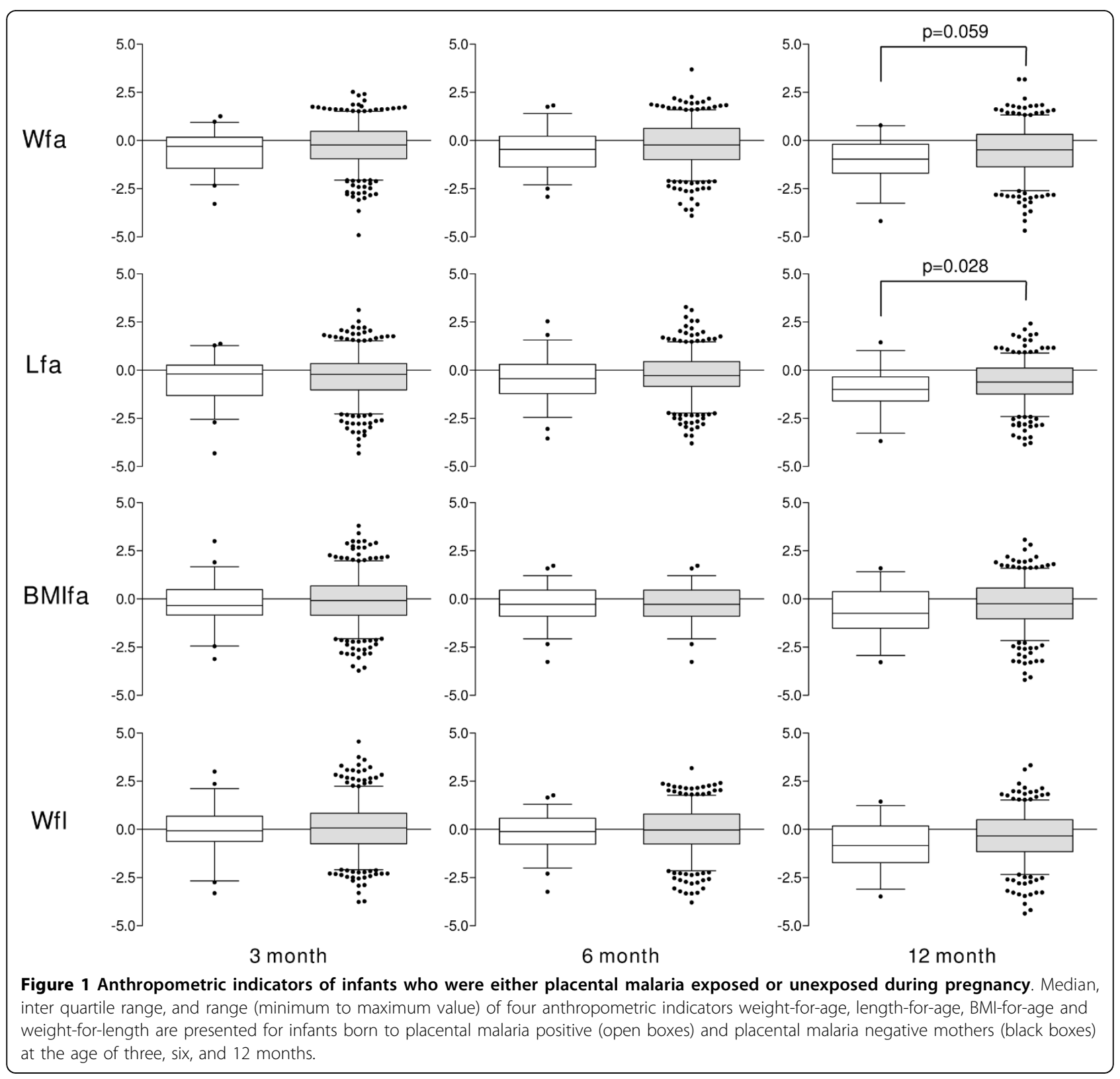


Table 2 Association of placental malaria* and anthropometric indicators of infants

\begin{tabular}{|c|c|c|c|}
\hline $\begin{array}{l}\text { Anthropometric } \\
\text { indicator }\end{array}$ & $\begin{array}{c}\text { z-scores difference } \\
{[(\mathrm{PM}+)-(\mathrm{PM}-)]^{* *}}\end{array}$ & $\mathrm{Cl} 95 \%$ & $p$-value \\
\hline \multicolumn{4}{|l|}{ Weight-for-age } \\
\hline 1-3 pregnancies & -0.43 & $-0.80 ;-0.07$ & 0.019 \\
\hline$\geq 4$ pregnancies & 0.02 & $-0.44 ; 0.48$ & 0.930 \\
\hline \multicolumn{4}{|l|}{ Weight-for-length } \\
\hline 1-3 pregnancies & -0.47 & $-0.84 ;-0.10$ & 0.013 \\
\hline$\geq 4$ pregnancies & 0.03 & $-0.44 ; 0.50$ & 0.903 \\
\hline \multicolumn{4}{|l|}{ BMI-for-age } \\
\hline 1-3 pregnancies & -0.57 & $-0.84 ;-0.10$ & 0.012 \\
\hline$\geq 4$ pregnancies & 0.03 & $-0.43 ; 0.50$ & 0.889 \\
\hline \multicolumn{4}{|l|}{ Length-for-age } \\
\hline All parities & -0.11 & $-0.37 ; 0.15$ & 0.405 \\
\hline
\end{tabular}

* Total of past, chronic and active placental malaria (PM)

**Difference in $z$-scores of PM exposed and unexposed infants ( $z$-score $(P M+)$ - $z$-score (PM-))

The table presents the results of the Generalized Estimating Equations models investigating a possible association of exposure to maternal PM during pregnancy and anthropometric indicators (weight-for-age (wfa), weight-forlength (wfl), BMI-for-age (BMIfa) and length-for-age (Ifa)) of the infants. 1,488 (PM+:135, PM-:1353) z-scores for each of four anthropometric indicators were included in the GEE model (1-3 pregnancies: 833 observations (PM+:86, PM:747); $\geq 4$ pregnancies: 655 observations (PM+: 49, PM-: 606)). The models account for multiple weight and length measurements at three, six and 12 months of age and confounding factors such as moderate low birth weight below $(2,000 \mathrm{~g}-2,499 \mathrm{~g})$, infant's age, sex, birth month and year, and duration of maternal education. Significant interactions between PM infection and parity were fitted for the first three anthropometric indicators (wfa, wfl, and BMIfa), but not for Ifa.

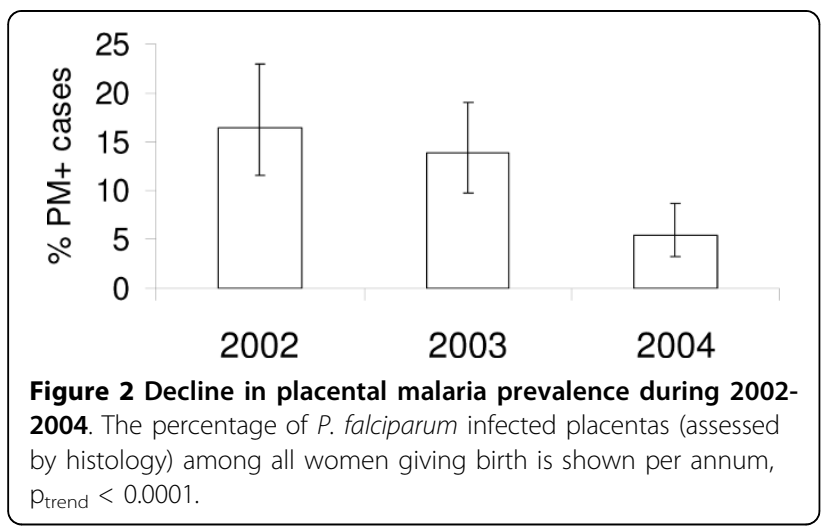

transmission had no effect on chronic infection prevalence (OR 1.12, CI $(0.42 ; 3.04), \mathrm{p}=0.82)$. A delayed seasonal effect could be observed for past infections in that they were significantly more likely to be diagnosed in the last three months of the malaria transmission season or thereafter through to March of the following year (OR 2.97, CI (1.33; 6.66), $\mathrm{p}<0.008$; [adjusted OR (AOR) 3.97 , CI $(1.67 ; 9.40)$, adjusted $\mathrm{p}$-value $\left(\mathrm{p}^{*}\right)=$ 0.005]) (Figure 3).

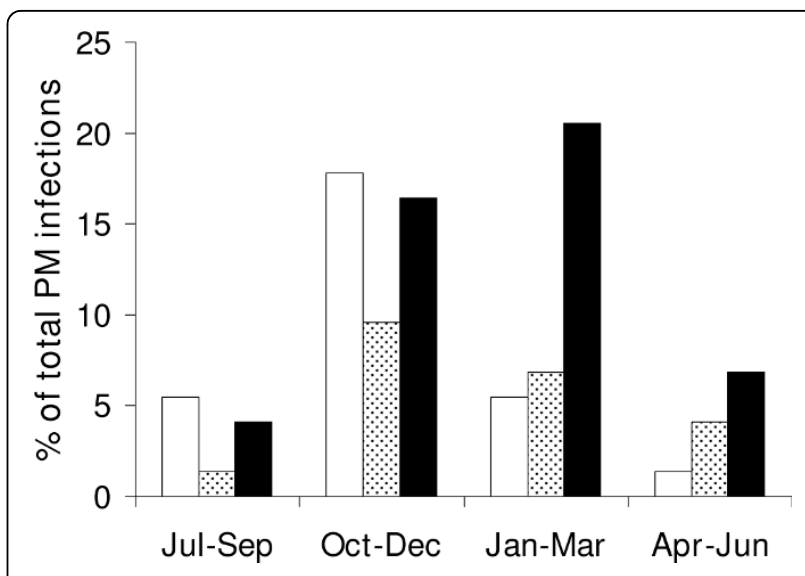

Figure 3 Seasonality of placental malaria. The percentage of acute (open bars), chronic (dotted bars) and past (black bars) placental malaria infections is shown over time. From January 2002 till December 2004 21/72 (29.2\%) were classified as acute, 16/72 (22.2\%) as chronic, and 35/72 (48.6\%) as past infection.

\section{Discussion}

By taking advantage of a cohort study specifically designed to recruit healthy babies, and subsequent analysis adjusting for moderate low birth weight, the direct impact of PM on the infant's size during the first year of life independent from LBW-associated effects was examined. The main aim of this study was to investigate if babies who were exposed to PM showed a significantly different growth pattern during infancy compared to babies who were not exposed to PM, when the babies in both groups had a similar weight distribution at birth. The finding that the birth weights of the PM+ and PMgroups were not significantly different suggests that we successfully enrolled babies of similar birth weight distribution in both groups. Therefore any PM effects on subsequent growth could not be accounted for by a lower starting birth weight in the PM+ group.

This study shows that first to third born infants of PM + mothers were significantly lighter, thinner and had lower BMIfa z-scores compared to infants of PMmothers. The analysis comprised all PM exposed infants disregarding the histological subgroup of PM. Since severity of pathological changes within the placenta, gestational age at infection or duration of infection are closely associated with PM subgroups, it is likely that the association of growth development might be different within the subgroups past, chronic and active PM. Unfortunately this study wasn't sufficiently powered to enable performance of such subgroup analyses.

PM exposed infants were 2.4 times more likely to be wasted at the age of three months and 3.1 times more likely to be underweight at the age of 12 months than infants born to PM- mothers. Since the described effect is independent of LBW, this suggests that the overall 
burden of PM may have been underestimated. In addition, it should be borne in mind that irrespective of PM status, and despite the exclusion of babies with low birth weight $(\leq 2,000 \mathrm{~g})$, infants recruited in the Sukuta cohort were significantly lighter, smaller, and had lower values for BMI than children of the world standard population. Any additional negative effect on nutritional status such as that we described here may therefore become even more relevant for these children.

Overall infants had significantly lower z-scores at 12 months compared to $\mathrm{z}$-scores at three month of age, an effect which might be explained by a change in feeding practice and increased mobility of the infant and therefore higher exposure to pathogens. A limitation of the study is that information on gestational age and breast feeding practices, an important correlate of postnatal growth, was not collected. However, most mothers exclusively breast feed for 6 months, and thereafter continue breast feeding alongside giving solid food past the age of 1 year. The possibility that the described association of PM and infant's growth development has been confounded by maternal height and BMI cannot be excluded. However, among those mothers with available data for height and BMI (39\%), median values were not significantly different between PM+ and PM- mothers.

The presented findings imply that the increased risk for poorer weight gain independent of LBW applies to the first to third born infants of PM+ mothers, but not for $\geq$ fourth born children. Gravidity effects have been described in studies analyzing for the effect of PM on subsequent susceptibility to malaria in early life $[34,45]$. These gravidity effects have been attributed to the higher malaria antigen load and greater degree of placental inflammation that is thought to occur in the lower gravidity states, since these woman have lower anti-chondroitin sulfate A antibody levels and thus less immunity against PM [45]. However gravidity related altered susceptibility to malaria itself is unlikely to account for the delayed growth in the PM exposed group in this study, since diagnosed malaria was rare in the $1^{\text {st }}$ year of life in this population. Therefore other immunological mechanisms need to be considered.

The inflammatory effects of PM are generally thought to bias the neonatal immune system towards a Th1 inflammatory response [46], and this immune bias could lead to more severe inflammation in response to other infectious diseases encountered in the $1^{\text {st }}$ year of life. Several groups have proposed that immunological tolerance or regulatory $\mathrm{T}$ cells might also be primed by PM, which might then result in altered susceptibility to malaria, and also have a non-specific immunosuppressive role $[47,48]$. Indeed, several studies have since shown that malaria-specific Tregs are primed by PM [49-52]. It has also been shown that non-specific Tregs can be induced by PM, possibly due to priming of innate responses by malaria antigens via pattern recognition receptors such as the toll like receptors [52]. Indeed, TLR mutations have been shown to play an important role in the outcome of pregnancy associated malaria, and in particular TLR-4 and -9 mutations are associated with increased risk of low birth weight in term infants [53]. Altered innate immunity in early life and increased non-specific Tregs could certainly enhance susceptibility to other pathogens and antigens and therefore result in poorer growth development. The number of all cause morbidity episodes between PM exposed and PM not exposed infants were not significantly different in the presented study, although numbers were small and the severity and duration of illness was not assessed.

One further mechanism as to how PM might influence early life development independent of birth weight is its effects on leptin levels. Leptin regulates appetite and metabolism, and during pregnancy the placenta acts as an additional source of leptin [54]. PM has been shown to cause a disruption in the relationship between leptin and birth weight [55], and although it is not known whether leptin responsiveness is later restored, an early lack of leptin responsiveness could certainly contribute to poor growth in PM+ children. Clearly the effect of PM on subsequent immunity in early life is a research an area of great interest, and the precise immunological effects have yet to be fully elucidated.

Several publications report a marked decline of malaria prevalence over the recent years in sub-Saharan Africa [56-60]. For The Gambia, a retrospective record based analysis of malaria incidence spanning from 1999 to 2007 carried out in a region that included the catchment area of Sukuta Health Centre, observed a marked decline in the annual number of admissions and deaths attributed to malaria, particularly since 2003 [61]. Malaria prevalence surveys carried out at the end of the transmission season 2007/8 document unprecedentedly low levels of malaria in the Gambia and Guinea Bissau [62]. The presented data on histology-based diagnosis of PM support this further, documenting a decline in malaria incidence. While in 2002 the study site could have been classified as a high transmission region, based on a PM prevalence of $16.5 \%$, PM prevalence decreased markedly to $5.4 \%$ in 2004, indicative of low levels of malaria transmission [6]. Since yearly rainfall data for the Gambia, including the study area Sukuta, do not indicate a significant reduction in average rainfall during the study period, it is rather unlikely that changes in rainfall could account for the observed steep decline in PM prevalence.

A steady increase in bednet coverage in The Gambia for children $<5$ years from $42 \%$ in 2000 to $63 \%$ in 2005 [63] may have contributed to this decline, although in this study bednet usage was comparable among PM+ and PM- mothers. Intermittent preventative treatment 
for malaria in pregnancy with sulphadoxine-pyrimethamine (Fansidar ${ }^{\circ}$ ) was introduced at Sukuta HC antenatal clinic in 2005 and therefore cannot account for the decline in PM.

Earlier reports suggest a delayed seasonal effect on PM prevalence in areas of seasonal transmission [13], which is confirmed by the presented data. Using placental histology it was demonstrated that the vast majority of PM cases detected in the non transmission season are attributable to past placental infections, reaching a peak in January to March. As expected, those cases classified as acute PM closely follow the seasonal transmission pattern, while no significant seasonal variation could be observed in the incidence of chronic PM.

A previous study in a semi-urban area of The Gambia showed socio-economic factors, but not education, to be significantly associated with increased risk for $P$. falciparum infection [64]. In particular, poor and crowded housing conditions were identified as risk factors. While crowding was also associated with PM in the presented dataset, poorer maternal education (duration of schooling) was identified as an additional risk factor for PM. Adequate maternal education may therefore help reducing the burden of PM.

\section{Conclusions}

In summary, it was shown that PM exposure during pregnancy has a negative impact on the infant's growth development for first to third born infants that is independent of, but additional to, the well-documented deleterious effects of LBW associated with PM $[4,5,20,23,24,65]$ This suggests that the burden of PM on the infant's development may have been underestimated, which points out the paramount importance of control strategies for malaria in pregnancy. The main findings of this study, the additional impact of PM on development of infants and the decline in PM over time, illustrate the importance of epidemiological data in designing control measures and determining treatment priorities.

Additional file 1: Risk factors for placental malaria for mothers
delivering at maternity ward of Sukuta Health Centre from January
2002 to July 2005, multivariable analysis for 2002-04. The table
provided represents the results of the statistical analysis assessing the risk
factors for placental malaria (PM).
Click here for file
[http://www.biomedcentral.com/content/supplementary/1475-2875-9-16-
S1.DOC]
Additional file 2: Association of placental malaria with maternal
anaemia and baby's characteristics at birth. The table in this file
shows the results of the statistical analysis investigating if maternal and
baby's outcome characteristics at birth were different between PM+ and
PM- groups.
Click here for file
[http://www.biomedcentral.com/content/supplementary/1475-2875-9-16-
S2.DOC]

\section{Acknowledgements}

The authors thank the study participants, the staff at Sukuta Health Centre and Sukuta Hospital, in particular Ms Sally Savage. Momadou Jammeh (Royal Victoria Teaching Hospital, Banjul, The Gambia), Jean-Marie Dangou (Institute Pasteur, Dakar, Senegal) and Modou Jallow, MRC, The Gambia performed the placental histology slide preparation and reading. The authors acknowledge Drs. Arnaud Marchant (Institute for Medical Immunology, Université Libre de Bruxelles, Charleroi, Belgium), Steve Kaye (Jefferiss Research Trust Laboratory, Imperial College London, UK) for their contribution to the Sukuta cohort, and Michael Walther (MRC, The Gambia) for conscientious proof reading of the manuscript.

This study was funded by the MRC (UK) Laboratories, Fajara, The Gambia.

\section{Author details}

${ }^{1}$ MRC Laboratories, Atlantic Boulevard, Fajara, PO Box 273 Banjul, The Gambia. ${ }^{2}$ South African Tuberculosis Vaccine Initiative, Institute of Infectious Diseases and Molecular Medicine, and School of Child and Adolescent Health, University of Cape Town, Observatory, South Africa. ${ }^{3} \mathrm{MRC}$

Epidemiology Resource Centre, University of Southampton, Southampton General Hospital, Southampton, UK. ${ }^{4}$ Immunization Department, Health Protection Agency Centre for Infections, Colindale Avenue, London, UK. ${ }^{5}$ Adventist Community Services of Alaska, 6100 O'Malley Road, Anchorage, USA. ${ }^{6}$ Department of Pediatrics, Bronx-Lebanon Hospital Center, 1650 Grand Concourse, Bronx, New York, USA. ${ }^{7}$ Epidemiology and Surveillance Unit, Centre for Infectious Diseases Control, National Institute for Public Health and the Environment, Bilthoven, Netherlands. ${ }^{8} \mathrm{MRC}$ Human Immunology Unit, Weatherall Institute of Molecular Medicine, John Radcliffe Hospital, Oxford, UK.

\section{Authors' contributions}

DJCM, MVDS, HW, SRJ, and KLF contributed to the conception and design of the study. DJCM, PW, MSP, OO, ET, MVDS, and KLF contributed to study implementation and data collection. BW, DJCM, SC performed data analyses and interpreted the data. BW drafted the manuscript and DJCM, SC, MVDS, $\mathrm{HW}, \mathrm{SRJ}$, and KLF revised it critically. All authors read and approved the final manuscript.

\section{Competing interests}

The authors declare that they have no competing interests.

Received: 11 September 2009

Accepted: 14 January 2010 Published: 14 January 2010

\section{References}

1. Walther B, Walther M: What does it take to control malaria?. Ann Trop Med Parasitol 2007, 101:657-672.

2. WHO: World malaria report 2008. Geneva, Switzerland: WHO Press 2008.

3. Korenromp EL: Malaria incidence estimates at country level for the year 2004 - proposed estimates and draft report for the roll back malaria monitoring and evaluation reference group merg task force on malaria morbidity. Geneva, Roll Back Malaria, World Health Organization 2004.

4. Steketee RW, Nahlen BL, Parise ME, Menendez C: The burden of malaria in pregnancy in malaria-endemic areas. Am J Trop Med Hyg 2001, 64:28-35.

5. Guyatt HL, Snow RW: Impact of malaria during pregnancy on low birth weight in sub-saharan africa. Clin Microbiol Rev 2004, 17:760-769.

6. Desai M, ter Kuile FO, Nosten F, McGready R, Asamoa K, Brabin B, Newman RD: Epidemiology and burden of malaria in pregnancy. Lancet Infect Dis 2007, 7:93-104.

7. Kasumba IN, Nalunkuma AJ, Mujuzi G, Kitaka FS, Byaruhanga R, Okong P, Egwang TG: Low birthweight associated with maternal anaemia and plasmodium falciparum infection during pregnancy, in a peri-urban/ urban area of low endemicity in uganda. Ann Trop Med Parasitol 2000, 94:7-13.

8. Brabin B, Piper C: Anaemia- and malaria-attributable low birthweight in two populations in papua new guinea. Ann Hum Biol 1997, 24:547-555.

9. Duffy $P E$, Fried M: Malaria during pregnancy: Parasites, antibodies and chondroitin sulphate a. Biochem Soc Trans 1999, 27:478-482.

10. Beeson JG, Amin N, Kanjala M, Rogerson SJ: Selective accumulation of mature asexual stages of plasmodium falciparum-infected erythrocytes in the placenta. Infect Immun 2002, 70:5412-5415. 
11. Fried M, Duffy PE: Adherence of plasmodium falciparum to chondroitin sulfate a in the human placenta. Science 1996, 272:1502-1504.

12. Fried M, Domingo GJ, Gowda CD, Mutabingwa TK, Duffy PE: Plasmodium falciparum: Chondroitin sulfate $a$ is the major receptor for adhesion of parasitized erythrocytes in the placenta. Exp Parasitol 2006, 113:36-42.

13. Brabin BJ, Romagosa C, Abdelgalil S, Menendez C, Verhoeff FH, MCGready R, Fletcher KA, Owens S, D'Alessandro U, Nosten F, Fischer PR, Ordi J: The sick placenta-the role of malaria. Placenta 2004, 25:359-378.

14. Moormann AM, Sullivan AD, Rochford RA, Chensue SW, Bock PJ, Nyirenda T, Meshnick SR: Malaria and pregnancy: Placental cytokine expression and its relationship to intrauterine growth retardation. J Infect Dis 1999, 180:1987-1993.

15. Menendez C, Ordi J, Ismail MR, Ventura PJ, Aponte JJ, Kahigwa E, Font F, Alonso PL: The impact of placental malaria on gestational age and birth weight. J Infect Dis 2000, 181:1740-1745.

16. Suguitan AL Jr, Cadigan TJ, Nguyen TA, Zhou A, Leke RJ, Metenou S, Thuita L, Megnekou R, Fogako J, Leke RG, Taylor DW: Malaria-associated cytokine changes in the placenta of women with pre-term deliveries in yaounde, cameroon. Am J Trop Med Hyg 2003, 69:574-581.

17. Shulman CE, Marshall T, Dorman EK, Bulmer JN, Cutts F, Peshu N, Marsh K: Malaria in pregnancy: Adverse effects on haemoglobin levels and birthweight in primigravidae and multigravidae. Trop Med Int Health 2001, 6:770-778

18. Rogerson SJ, Pollina E, Getachew A, Tadesse E, Lema VM, Molyneux ME: Placental monocyte infiltrates in response to plasmodium falciparum malaria infection and their association with adverse pregnancy outcomes. Am J Trop Med Hyg 2003, 68:115-119.

19. Rogerson SJ: Sequestration: Causes and consequences. Redox Rep 2003, 8:295-299.

20. Sarr D, Marrama L, Gaye A, Dangou JM, Niang M, Mercereau-Puijalon O, Lehesran JY, Jambou R: High prevalence of placental malaria and low birth weight in sahelian periurban area. Am J Trop Med Hyg 2006, 75:171177

21. Kramer MS: Determinants of low birth weight: Methodological assessment and meta-analysis. Bull World Health Organ 1987, 65:663-737.

22. McCormick MC: The contribution of low birth weight to infant mortality and childhood morbidity. N Engl J Med 1985, 312:82-90.

23. Guyatt HL, Snow RW: Malaria in pregnancy as an indirect cause of infant mortality in sub-saharan africa. Trans R Soc Trop Med Hyg 2001, 95:569576.

24. Greenwood AM, Armstrong JR, Byass P, Snow RW, Greenwood BM: Malaria chemoprophylaxis, birth weight and child survival. Trans $R$ Soc Trop Med Hyg 1992, 86:483-485.

25. Luxemburger C, McGready R, Kham A, Morison L, Cho T, Chongsuphajaisiddhi T, White NJ, Nosten F: Effects of malaria during pregnancy on infant mortality in an area of low malaria transmission. Am J Epidemiol 2001, 154:459-465.

26. Murphy SC, Breman JG: Gaps in the childhood malaria burden in africa: Cerebral malaria, neurological sequelae, anemia, respiratory distress, hypoglycemia, and complications of pregnancy. Am J Trop Med Hyg 2001, 64:57-67.

27. Garner $P$, Kramer MS, Chalmers I: Might efforts to increase birthweight in undernourished women do more harm than good?. Lancet 1992, 340:1021-1023

28. van Geertruyden JP, Thomas F, Erhart A, D'Alessandro U: The contribution of malaria in pregnancy to perinatal mortality. Am J Trop Med Hyg 2004 71:35-40.

29. Sande van der MA, Kaye $S$, Miles DJ, Waight $P$, Jeffries DJ, Ojuola OO, Palmero M, Pinder M, Ismaili J, Flanagan KL, Aveika AA, Zaman A, RowlandJones S, McConkey SJ, Whittle HC, Marchant A: Risk factors for and clinical outcome of congenital cytomegalovirus infection in a peri-urban westafrican birth cohort. PLOS ONE 2007, 2:e492.

30. Kalanda BF, van Buuren S, Verhoeff FH, Brabin BJ: Catch-up growth in malawian babies, a longitudinal study of normal and low birthweight babies born in a malarious endemic area. Early Hum Dev 2005, 81:841850

31. Barker DJP: Fetal and infant origins of disease London: BMJ Books 1992

32. Ashworth $\mathrm{A}$ : Effects of intrauterine growth retardation on mortality and morbidity in infants and young children. Eur J Clin Nutr 1998, 52(1):S3441, discussion S41-32.
33. Victora CG, Smith PG, Vaughan JP, Nobre LC, Lombardi C, Teixeira AM, Fuchs SM, Moreira LB, Gigante LP, Barros FC: Influence of birth weight on mortality from infectious diseases: A case-control study. Pediatrics 1988, 81:807-811.

34. Schwarz NG, Adegnika AA, Breitling LP, Gabor J, Agnandji ST, Newman RD, Lell B, Issifou S, Yazdanbakhsh M, Luty AJ, Kremsner PG, Grobusch MP: Placental malaria increases malaria risk in the first 30 months of life. Clin Infect Dis 2008, 47:1017-1025.

35. Duijts L, Bakker-Jonges LE, Labout JA, Jaddoe WW, Hofman A, Steegers EA, van Dongen JJ, Hooijkaas $\mathrm{H}$, Moll HA: Fetal growth influences lymphocyte subset counts at birth: The generation $r$ study. Neonatology 2008, 95:149156.

36. Schim van der Loeff MF, Sarge-Njie R, Ceesay $S$, Awasana AA, Jaye $P$, Sam O, Jaiteh KO, Cubitt D, Milligan P, Whittle HC: Regional differences in hiv trends in the gambia: Results from sentinel surveillance among pregnant women. Aids 2003, 17:1841-1846.

37. Ismail MR, Ordi J, Menendez C, Ventura PJ, Aponte JJ, Kahigwa E, Hirt R, Cardesa A, Alonso PL: Placental pathology in malaria: A histological, immunohistochemical, and quantitative study. Hum Pathol 2000, 31:8593.

38. WHO: Who child growth standards: Length/height-for-age, weight-forage, weight-for-length, weight-for-height and bodymass index-for-age: Methods and development. World Health Organization, Geneva 2006.

39. Moore SE, Collinson AC, Tamba N'Gom P, Aspinall R, Prentice AM: Early immunological development and mortality from infectious disease in later life. Proc Nutr Soc 2006, 65:311-318.

40. Ceesay SM, Prentice AM, Cole TJ, Foord F, Weaver LT, Poskitt EM, Whitehead RG: Effects on birth weight and perinatal mortality of maternal dietary supplements in rural gambia: 5 year randomised controlled trial. Bmj 1997, 315:786-790.

41. Brabin BJ, Hakimi M, Pelletier D: An analysis of anemia and pregnancyrelated maternal mortality. J Nutr 2001, 131:604S-614S, discussion 614S6155 .

42. Hirve SS, Ganatra BR: Determinants of low birth weight: A community based prospective cohort study. Indian Pediatr 1994, 31:1221-1225.

43. von Tempelhoff GF, Heilmann L, Rudig L, Pollow K, Hommel G, Koscielny J: Mean maternal second-trimester hemoglobin concentration and outcome of pregnancy: A population-based study. Clin Appl Thromb Hemost 2008, 14:19-28.

44. Shulman CE, Dorman EK, Bulmer JN: Malaria as a cause of severe anaemia in pregnancy. Lancet 2002, 360:494.

45. Mutabingwa TK, Bolla MC, Li JL, Domingo GJ, Li X, Fried M, Duffy PE: Maternal malaria and gravidity interact to modify infant susceptibility to malaria. PLoS Med 2005, 2:e407.

46. Broen K, Brustoski K, Engelmann I, Luty AJ: Placental plasmodium falciparum infection: Causes and consequences of in utero sensitization to parasite antigens. Mol Biochem Parasitol 2007, 151:1-8.

47. Le Hesran JY, Cot M, Personne P, Fievet N, Dubois B, Beyeme M, Boudin C, Deloron P: Maternal placental infection with plasmodium falciparum and malaria morbidity during the first 2 years of life. Am J Epidemiol 1997 146:826-831

48. Cot M, Le Hesran JY, Staalsoe T, Fievet N, Hviid L, Deloron P: Maternally transmitted antibodies to pregnancy-associated variant antigens on the surface of erythrocytes infected with plasmodium falciparum: Relation to child susceptibility to malaria. Am J Epidemiol 2003, 157:203-209.

49. Brustoski K, Moller U, Kramer M, Hartgers FC, Kremsner PG, Krzych U, Luty AJ: Reduced cord blood immune effector-cell responsiveness mediated by cd4+ cells induced in utero as a consequence of placental plasmodium falciparum infection. J Infect Dis 2006, 193:146-154.

50. Malhotra I, Dent A, Mungai P, Wamachi A, Ouma JH, Narum DL, Muchiri E, Tisch DJ, King CL: Can prenatal malaria exposure produce an immune tolerant phenotype? A prospective birth cohort study in kenya. PLOS Med 2009, 6:e1000116.

51. Bisseye C, Sande van der M, Morgan WD, Holder AA, Pinder M, Ismaili J: Plasmodium falciparum infection of the placenta impacts on the $t$ helper type 1 (th1)/th2 balance of neonatal $t$ cells through $\mathrm{cd} 4(+) \mathrm{cd} 25$ (+) forkhead box $\mathrm{p} 3(+)$ regulatory t cells and interleukin-10. Clin Exp Immunol 2009, 158:287-293.

52. Flanagan $\mathrm{K}$, Halliday A, Burl S, Landgraf $\mathrm{K}$, Jagne YJ, Noho-Konteh F, Townend J, Miles DJC, Sande van der M, Whittle H, Rowland-Jones S: The 
effect of placental malaria infection on cord blood and maternal immunoregulatory responses at birth. Eur I Immunol

53. Mockenhaupt FP, Cramer JP, Hamann L, Stegemann MS, Eckert J, Oh NR, Otchwemah RN, Dietz E, Ehrhardt S, Schroder NW, Bienzle U, Schumann RR: Toll-like receptor (tr) polymorphisms in african children: Common tlr-4 variants predispose to severe malaria. Proc Natl Acad Sci USA 2006, 103:177-182.

54. Linnemann K, Malek A, Schneider H, Fusch C: Physiological and pathological regulation of feto/placento/maternal leptin expression. Biochem Soc Trans 2001, 29:86-90.

55. Kabyemela ER, Fried M, Kurtis JD, Mutabingwa TK, Duffy PE: Fetal responses during placental malaria modify the risk of low birth weight. Infect Immun 2008, 76:1527-1534.

56. Nyarango PM, Gebremeskel T, Mebrahtu G, Mufunda J, Abdulmumini U, Ogbamariam A, Kosia A, Gebremichael A, Gunawardena D, Ghebrat Y, Okbaldet Y: A steep decline of malaria morbidity and mortality trends in eritrea between 2000 and 2004: The effect of combination of control methods. Malar J 2006, 5(33).

57. Bhattarai A, Ali AS, Kachur SP, Martensson A, Abbas AK, Khatib R, AlMafazy AW, Ramsan M, Rotllant G, Gerstenmaier JF, Molteni F, Abdulla S, Montgomery SM, Kaneko A, Bjorkman A: Impact of artemisinin-based combination therapy and insecticide-treated nets on malaria burden in zanzibar. PLoS Med 2007, 4:e309.

58. Okiro EA, Hay SI, Gikandi PW, Sharif SK, Noor AM, Peshu N, Marsh K, Snow RW: The decline in paediatric malaria admissions on the coast of kenya. Malar J 2007, 6:151.

59. Rodrigues A, Schellenberg JA, Kofoed PE, Aaby P, Greenwood B: Changing pattern of malaria in bissau, guinea bissau. Trop Med Int Health 2008, 13:410-417.

60. O'Meara WP, Bejon P, Mwangi TW, Okiro EA, Peshu N, Snow RW, Newton CR, Marsh K: Effect of a fall in malaria transmission on morbidity and mortality in kilifi, kenya. Lancet 2008, 372:1555-1562.

61. Ceesay SJ, Casals-Pascual C, Erskine J, Anya SE, Duah NO, Fulford AJ, Sesay SS, Abubakar I, Dunyo S, Sey O, Palmer A, Fofana M, Corrah T, Bojang KA, Whittle HC, Greenwood BM, Conway DJ: Changes in malaria indices between 1999 and 2007 in the gambia: A retrospective analysis. Lancet 2008, 372:1545-1554.

62. Satoguina J, Walther B, Drakeley C, Nwakanma D, Oriero EC, Correa S, Corran P, Conway DJ, Walther M: Comparison of surveillance methods applied to a situation of low malaria prevalence at rural sites in the gambia and guinea bissau. Malar J 2009, 8:274.

63. (GBOS) GBoS: The gambia multiple indicator cluster survey $2005 / 2006$, report, banjul. 2007.

64. Koram KA, Bennett S, Adiamah JH, Greenwood BM: Socio-economic risk factors for malaria in a peri-urban area of the gambia. Trans $R$ Soc Trop Med Hyg 1995, 89:146-150.

65. Kassam SN, Nesbitt S, Hunt LP, Oster N, Soothill P, Sergi C: Pregnancy outcomes in women with or without placental malaria infection. Int $J$ Gynaecol Obstet 2006, 93:225-232.

doi:10.1186/1475-2875-9-16

Cite this article as: Walther et al:: Placental Malaria is associated with reduced early life weight development of affected children independent of low birth weight. Malaria Journal 2010 9:16.

\section{Publish with BioMed Central and every scientist can read your work free of charge}

"BioMed Central will be the most significant development for disseminating the results of biomedical research in our lifetime. "

Sir Paul Nurse, Cancer Research UK

Your research papers will be:

- available free of charge to the entire biomedical community

- peer reviewed and published immediately upon acceptance

- cited in PubMed and archived on PubMed Central

- yours - you keep the copyright 